\title{
EL MATRIMONIO HOMOSEXUAL: UNA VISIÓN INTERDISCIPLINAR
}

\section{The Homosexual Marriage: An Interdisciplinary Vision}

\author{
Flavio Gutiérrez Velasco \\ Universidad Femenina Sagrado Corazón (UNIFE): flaviogutierrezv@unife.pe \\ https://orcid.org/ 0000-0002-4902-229X \\ Nuccia Seminario Hurtado \\ Abogada por la Universidad Femenina del Sagrado Corazón.nuccia_sh@hotmail.com \\ https://orcid.org/0000-0002-1805-7780
}

\begin{abstract}
RESUMEN
El presente artículo aborda el matrimonio homosexual en el siglo XXI, en una perspectiva interdisciplinar, desde una visión holística. En el ámbito sociocultural esta es una realidad que no se puede desconocer; en lo jurídico ha sido elevado a la categoría de matrimonio en muchas legislaciones; en lo antropológico hay concepciones a favor y en contra; y en el plano religioso se lo aborda desde la visión de la iglesia católica y de la Iglesia de Jesucristo de los Santos de los Últimos Días.

\section{Palabras clave:}

Homosexualidad, matrimonio, dignidad humana, igualdad, protección, minorías.

ABSTRACT

This paper addresses gay marriage in the 21 st century, from an interdisciplinary perspective, from a holistic perspective. In the sociocultural sphere this is a reality that cannot be ignored; Legally, it has been elevated to the status of marriage in many laws; in the anthropological there are conceptions for and against; and on the religious level it is approached from the vision of the Catholic Church and the Church of Jesus Christ of Latter-day Saints.
\end{abstract}

\section{Keywords:}

Homosexuality, marriage, human dignity, equality, protection, minorities. 


\section{INTRODUCCIÓN}

La concepción del matrimonio de parejas homosexuales ha dado un giro en los estudios antropológicos, socioculturales, jurídicos e incluso religiosos, porque tienen como finalidad salvaguardar y proteger la dignidad de la persona humana y su libertad de elección sexual. Este enfoque tiene un carácter interdisciplinar de las concepciones antropológicas, socioculturales y teológicas en nuestra cultura occidental, puesto que la persona es una unidad biopsico-social y es necesario respetar las distintas posturas sobre el matrimonio de dos personas del mismo sexo, fundándose en el respeto, unión y tolerancia.

Por ello, el presente artículo denota una visión interdisciplinaria sobre el matrimonio de dos personas del mismo sexo, a fin de determinar elementos comunes, teorías y posiciones que se encuentren debidamente motivadas con el fin de tener una visión holística del matrimonio homosexual

Como parte importante de este estudio se analiza la fundamentación teológica por parte de la Iglesia Católica y la Iglesia de Jesucristo de los Santos de los Últimos Días, ya que se considera importante esclarecer la opinión y estudio teológico que realizan ambas iglesias.

\section{EL MATRIMONIO HOMOSEXUAL EN EL SIGLO XX}

\section{Aspecto social}

El matrimonio se ha configurado durante años como el origen del núcleo familiar, de ahí que su regulación se considere tan relevante en lo relativo al desarrollo personal y social del individuo. A pesar de ello, actualmente no se constituye como el modelo único de familia, pues cada vez se registran más formas de relacionarse y elaborar un entorno familiar, y la perspectiva desde la cual se puede observar este escenario va a variar de unos lugares a otros (Tordesillas, 2016, p.77)

Esto quiere decir, que, en la actualidad desde el punto de vista social, puede ser considerado como matrimonio la unión de dos personas que desean constituir una familia y de esa manera formar parte de un duplo. Cuando nos referimos a la unión de "dos personas" recalcamos que no importa el género de estas al momento de contraer nupcias, pudiendo ser la unión de dos personas de diferentes sexos (heterosexual) o la de dos personas del mismo sexo (homosexual).

Sin embargo, debemos comprender de manera profunda ¿qué es la homosexualidad?Y ¿por qué actualmente se protege el matrimonio de personas del mismo sexo?

Sobre la homosexualidad y su entorno, Chomali et al (2008) expresan que:

La persona "se descubre" homosexual (...) en el contexto de su desarrollo sicológico y afectivo se reconoce atraída hacia personas del mismo sexo y siente que ello constituye un salirse del orden: un desorden. (...) Otra aclaración de importancia es que la tendencia homosexual no es una perversión, puesto que las perversiones se relacionan con los comportamientos que buscan transgredir normas, y no es 
legítimo suponer que una persona con tendencia homosexual vaya de suyo a hacerlo. ${ }^{1}$ (p.31)

Es decir, la homosexualidad es una orientación que es determinada como la atracción hacia una persona del mismo sexo, y desde un punto de vista social advierte el papel que determinan las interacciones sociales, pues el homosexual que actúa de acuerdo con la orientación sexual entra en el campo de las interacciones sociales, ya que constituyen complejas formas colectivas, que tal vez podamos llamar cultura por sus propios hábitos, usos y costumbres que presentan, y que además, son inherentes a ellos.

Los cambios sociales producidos a finales del siglo XX y principios del XXI, en relación al reconocimiento de la cultura homosexual, "han comenzado a abrir la puerta en algunas legislaciones modernas a unos enlaces en los que dos personas, no ya sólo hombre y mujer, pueden unirse por medio del matrimonio y/o figuras análogas" (Tordesillas, p.77), sino también personas del mismo sexo también pueden contraer nupcias.

El matrimonio homosexual "a partir de las transformaciones sociales sobre los criterios de la constitución de la familia, habida cuenta de tantas familias irregulares o funcionales" (Arrieta, 2016, p.14), es decir la constitución e instauración del matrimonio de las personas del mismo sexo, es parte de un fenómeno social, que, con el tiempo, se ha debido amparar y regular.

\section{Aspecto jurídico}

Bajo las anteriores consideraciones, es pertinente traer a colación el marco normativo internacional y, a partir de este, analizar si efectivamente las parejas homosexuales, son titulares del derecho a contraer matrimonio (Matzumoto y coronel, 2013, p. 21), mediante el desarrollo jurisprudencial del sistema de protección universal y regional de los derechos humanos.

Es preciso señalar que el matrimonio de las personas del mismo sexo apuntala al reconocimiento de derecho humano, por los fundamentos siguientes: principio de dignidad humana, derecho a la igualdad y no discriminación, derecho a la familia. Bajo estas concepciones se ha determinado la protección internacional del matrimonio igualitario.

En primer lugar, el principio de dignidad humana está basado en "uno de los valores más fundamentales de la persona humana entendida como ser racional, esto es, el reconocimiento de su dignidad. Es así como este Tribunal ha señalado en otras oportunidades que ese valor es consustancial a los atributos de la persona, y es, en consecuencia, un derecho humano fundamental oponible erga omnes como expresión de un interés colectivo de la comunidad internacional en su conjunto." 2 Por tales motivos, las personas son titulares de derechos exclusivos que parten del reconocimiento de su dignidad humana.

La Declaración Universal de los Derechos Humanos ${ }^{3}$ en su artículo 1 denota que: "Todos los seres humanos

1 El subrayado es nuestro para esclarecer que la homosexualidad no debe ser relacionada como un comportamiento anormal o pervertido, salvaguardando el respeto hacia dicha comunidad.

2 Opinión Consultiva OC-24/17, fundamento jurídico 85

3 Acto declarativo adoptado por la Asamblea General de las Naciones Unidas en su Resolución 217 A (III), el 10 de diciembre de 1948 
nacen libres e iguales en dignidad y derechos y, dotados como están de razón y conciencia, deben comportarse fraternalmente los unos con los otros".

En segundo lugar, a propósito del derecho a la igualdad y no discriminación, la Corte Interamericana ha señalado que "la noción de igualdad se desprende directamente de la unidad de naturaleza del género humano y es inseparable de la dignidad esencial de la persona, frente a la cual es incompatible toda situación que, por considerar superior a un determinado grupo, conduzca a tratarlo con privilegio; o que, a la inversa, por considerarlo inferior, lo trate con hostilidad o de cualquier forma lo discrimine del goce de derechos (...)"4

La Declaración Universal de los Derechos Humanos en su artículo 7 señala que "Todos son iguales ante la ley y tienen, sin distinción, derecho a igual protección de la ley. Todos tienen derecho a igual protección contra toda discriminación que infrinja esta Declaración y contra toda provocación a tal discriminación.", y, la Convención Americana de Derechos Humanos ${ }^{5}$ en su artículo 24 señala que "Todas las personas son iguales ante la ley. En consecuencia, tienen derecho sin discriminación a la igual protección de la ley", es decir, la igualdad de derechos del hombre y la mujer al disfrute de todos los derechos humanos es uno de los principios fundamentales reconocidos por el derecho internacional y recogido en los principales instrumentos internacionales sobre derechos humanos. ${ }^{6}$

Seguidamente, señalamos que dichos instrumentos jurídicos internacionales protegen al matrimonio entre dos personas de diferentes o del mismo sexo, no existiendo ningún tipo de discriminación por sexo o género, pues " resulta esencial fortalecer el respeto por el otro: es perfectamente posible que personas con distintos patrones sexuales establezcan vínculos de convivencia social, de amistad y solidaridad, comprendiendo y aceptando cada uno el patrón sexual del otro, sin tratar de intervenir en ello, para cambiarlo; es decir, consolidar el respeto mutuo." (Boscan, 2008, p.61)

Finalmente, el derecho a una familia apuntala al reconocimiento de las personas homosexuales a constituir sus propias familias mediante el acto del matrimonio, tal es su importancia que la Corte Interamericana de Derechos Humanos (CIDH) reconoció el matrimonio entre personas del mismo sexo e instó a los países de la región al reconocimiento de estos matrimonios, ya que ellos "deben reconocer y garantizar todos los derechos que se derivan de un vínculo familiar entre personas del mismo sexo", señaló la Corte, y para ello considera pertinente utilizar la figura del matrimonio y no otros formatos legales que podrían prolongar la discriminación."7

4 Opinión Consultiva OC-24/17, fundamento jurídico 61

5 Suscrita, tras la Conferencia Especializada Interamericana de Derechos Humanos, el 22 de noviembre de 1969

6 Información sustraída de Observación general № 16: La igualdad de derechos del hombre y la mujer al disfrute de los derechos económicos, sociales y culturales (artículo 3 del Pacto Internacional de Derechos Económicos, Sociales y Culturales). Recuperado de: https://www.escr-net.org/es/recursos/observacion-general-no-16-igualdad-derechos-del-hombre-y-mujer-al-disfrute-derechos7 Suscrita, tras la Conferencia Especializada Interamericana de Derechos Humanos, el 22 de noviembre de 1969

7 Diario El País. (11 de enero de 2018) "La Corte Interamericana falla a favor del matrimonio igualitario". Recuperado de: https://elpais.com/internacional/2018/01/10/mexico/1515624521_957175.html 
En el marco de protección de sistema interamericano, la Declaración Americana de los Derechos y Deberes del Hombre ${ }^{8}$, ha señalado en su artículo VI "Toda persona tiene derecho a constituir familia, elemento fundamental de la sociedad, y a recibir protección para ella" y la Convención Americana de Derechos Humanos en su artículo 17 inciso 2: "Se reconoce el derecho del hombre y la mujer a contraer matrimonio y a fundar una familia si tienen la edad y las condiciones requeridas para ello por las leyes internas, en la medida en que éstas no afecten al principio de no discriminación establecido en esta Convención" (el subrayado es nuestro).

Y, en el marco de la protección internacional, el Pacto Internacional de Derechos Civiles y Políticos ${ }^{9}$, establece en su artículo 23.1 que: "1. La familia es el elemento natural y fundamental de la sociedad y tiene derecho a la protección de la sociedad y del Estado. 22 2. Se reconoce el derecho del hombre y de la mujer a contraer matrimonio y a fundar una familia si tiene edad para ello. 3 . El matrimonio no podrá celebrarse sin el libre y pleno consentimiento de los contrayentes. 4. Los Estados Parte en el presente Pacto tomarán las medidas para asegurar la igualdad de derechos y de responsabilidades de ambos esposos en cuanto al matrimonio, durante el matrimonio y en caso de disolución del mismo. En caso de disolución, se adoptarán disposiciones que aseguren la protección necesaria los hijos."

Por todo lo anteriormente expuesto, algunos Estados han optado por regular el matrimonio entre dos personas del mismo sexo en su jurisdicción, partiendo de la fundamentación del reconocimiento de la dignidad humana y sus derechos fundamentales. A continuación, un cuadro comparativo de algunas legislaciones en Europa, Asia, África y América Latina que reconocieron el matrimonio entre dos personas del mismo sexo marcando un hito histórico y jurídico durante el siglo XXI.

\begin{tabular}{|c|c|c|}
\hline PAÍS & $\begin{array}{c}\text { AÑO DE } \\
\text { PROMUL- } \\
\text { GACIÓN }\end{array}$ & $\begin{array}{l}\text { COMENTARIOS SO- } \\
\text { BRE LA LEY }\end{array}$ \\
\hline $\begin{array}{l}\text { Países } \\
\text { Bajos }\end{array}$ & 2000 & $\begin{array}{l}\text { En el año 2000, Holan- } \\
\text { da aprobó la ley que } \\
\text { sería precursora de los } \\
\text { derechos de las parejas } \\
\text { homosexuales. Con } \\
\text { ella, por primera vez, } \\
\text { se permitió que dos } \\
\text { personas del mismo } \\
\text { sexo pudieran contraer } \\
\text { matrimonio civil (...) } \\
\text { (Martínez, 2016, } \\
\text { pp.234 235). }\end{array}$ \\
\hline Bélgica & 2003 & $\begin{array}{l}\text { El } 13 \text { de febrero de } \\
2003 \text {, en Bélgica se } \\
\text { aprueba la "Ley de } \\
\text { Matrimonio entre Per- } \\
\text { sonas del Mismo Sexo" } \\
\text { (Martínez, 2016, p. } \\
\text { 237), no obstante, tuvo } \\
\text { ciertas limitaciones en } \\
\text { la filiación y adopción. }\end{array}$ \\
\hline España & 2005 & $\begin{array}{l}\text { Mediante la Ley } \\
\text { 13/2005, de } 1 \text { de } \\
\text { julio del 2005, España } \\
\text { modifica el Código Civil } \\
\text { en materia de derecho } \\
\text { a contraer matrimonio, } \\
\text { reconociendo el matri - } \\
\text { monio de dos personas } \\
\text { del mismo sexo. }\end{array}$ \\
\hline Canadá & 2005 & $\begin{array}{l}\text { En Canadá se introdujo } \\
\text { el matrimonio de per- } \\
\text { sonas del mismo sexo } \\
\text { mediante la promul- } \\
\text { gación de la Ley de } \\
\text { matrimonio civil el } 20 \\
\text { de julio de } 2005 \text {. }\end{array}$ \\
\hline
\end{tabular}

8 Aprobada por la IX Conferencia Internacional Americana, 1948 en Colombia, Bogotá.

9 Adoptado y abierto a la firma, ratificación y adhesión por la Asamblea General en su resolución 2200 A (XXI), de 16 de diciembre de 1966 


\begin{tabular}{|c|c|c|}
\hline $\begin{array}{l}\text { Sudá- } \\
\text { frica }\end{array}$ & 2006 & $\begin{array}{l}\text { El matrimonio entre } \\
\text { personas del mismo } \\
\text { sexo en Sudáfrica ha } \\
\text { sido legal desde que } \\
\text { la promulgación de la } \\
\text { Ley de Unión Civil que } \\
\text { entró en vigor el } 30 \text { de } \\
\text { noviembre de } 2006 .\end{array}$ \\
\hline Suecia & 2009 & $\begin{array}{l}\text { En Suecia, el matri- } \\
\text { monio entre personas } \\
\text { del mismo sexo es } \\
\text { permitido desde el } 1 \text { de } \\
\text { mayo de } 2009 \text {, convir- } \\
\text { tiéndolo en el séptimo } \\
\text { país del mundo que } \\
\text { permite el matrimonio } \\
\text { de las personas homo- } \\
\text { sexuales. }\end{array}$ \\
\hline $\begin{array}{c}\text { Argen- } \\
\text { tina }\end{array}$ & 2010 & $\begin{array}{l}\text { En julio de } 2010 \text {, } \\
\text { Argentina se convirtió } \\
\text { en el primer país de } \\
\text { América Latina en } \\
\text { reconocer el derecho a } \\
\text { matrimonio entre per- } \\
\text { sonas del mismo sexo } \\
\text { a nivel nacional. El artí- } \\
\text { culo } 2 \text { de la Ley } 26.618 \\
\text { de Matrimonio Civil } \\
\text { (2010) (conocida como } \\
\text { la Ley de Matrimonio } \\
\text { Igualitario) establece } \\
\text { que "el matrimonio } \\
\text { tendrá los mismos } \\
\text { requisitos y efectos, } \\
\text { con independencia de } \\
\text { que los contrayentes } \\
\text { sean del mismo o de } \\
\text { diferente sexo"10 }\end{array}$ \\
\hline $\begin{array}{l}\text { Dina- } \\
\text { marca }\end{array}$ & 2012 & $\begin{array}{l}\text { En Dinamarca el matri- } \\
\text { monio entre personas } \\
\text { del mismo sexo está } \\
\text { regulado desde } 15 \text { de } \\
\text { junio de } 2012 \text { Por ello, } \\
\text { Dinamarca fue el undé- } \\
\text { cimo país del mundo } \\
\text { en legalizar el matrimo- } \\
\text { nio entre personas del } \\
\text { mismo sexo. }\end{array}$ \\
\hline
\end{tabular}

\begin{tabular}{|c|c|c|}
\hline Uruguay & 2013 & $\begin{array}{l}\text { En Uruguay mediante } \\
\text { Ley No } 19.075 \text { intitula- } \\
\text { da "Matrimonio Igua- } \\
\text { litario" se modifica el } \\
\text { artículo } 83 \text { del Código } \\
\text { Civil señalando que "El } \\
\text { matrimonio civil es la } \\
\text { unión permanente, con } \\
\text { arreglo a la ley, de dos } \\
\text { personas de distinto o } \\
\text { igual sexo."11 }\end{array}$ \\
\hline Brasil & 2012 & $\begin{array}{l}\text { En Brasil, una decisión } \\
\text { del Tribunal Supre- } \\
\text { mo Federal de } 2011 \\
\text { equiparó las parejas de } \\
\text { hecho homosexuales } \\
\text { a las heterosexuales. } \\
\text { Más adelante, el Supe- } \\
\text { rior Tribunal de Justicia } \\
\text { resolvió un recurso en } \\
\text { el sentido de que no } \\
\text { existía un obstáculo le- } \\
\text { gal para la celebración } \\
\text { de matrimonio entre } \\
\text { personas del mismo } \\
\text { sexo, ya que las dis- } \\
\text { posiciones del Código } \\
\text { Civil debían interpretar- } \\
\text { se de conformidad con } \\
\text { la Constitución (...) } \\
\text { (Arlettaz, 2015, p.70) }\end{array}$ \\
\hline Francia & 2013 & $\begin{array}{l}\text { Mediante la ley del } \\
17 \text { de mayo de } 2013 \\
\text { sobre el matrimonio } \\
\text { homosexual, Francia } \\
\text { se ha convertido en } \\
\text { el } 9^{\circ} \text { país europeo y } \\
\text { el } 14^{\circ} \text { en el mundo en } \\
\text { permitir el matrimonio } \\
\text { entre personas del } \\
\text { mismo sexo. Esta ley } \\
\text { abrió nuevos derechos } \\
\text { para el matrimonio, la } \\
\text { adopción y la herencia, } \\
\text { en nombre de los } \\
\text { principios de igualdad } \\
\text { y el reparto de las } \\
\text { libertades. }{ }^{12}\end{array}$ \\
\hline
\end{tabular}

10 "Ley 26.618 - Matrimonio Igualitario". Recuperado de: https://identidadydiversidad.adc.org.ar/normativa/ ley-26-618-matrimonio-igualitario-2010/

11 República del Uruguay. Publicado el Publicada D.O. 9 mayo/013 - № 28710 Ley № 19.075 "Matrimonio Igualitario." Recuperado de: https://legislativo.parlamento.gub.uy/temporales/leytemp1847694.htm

12 Gobierno Francés. "Le mariage pour tous". Recuperado de : https://www.gouvernement.fr/action/le-mariage-pour-tous 


\begin{tabular}{|c|l|l|}
\hline Colom- & & $\begin{array}{l}\text { Colombia enmarcó } \\
\text { bia } \\
\text { un hito mediante la } \\
\text { jurisprudencia de la } \\
\text { Corte Constitucional } \\
\text { la cual, mediante la } \\
\text { sentencia SU-2 14/16, } \\
\text { aprueba el matrimonio } \\
\text { civil entre parejas del } \\
\text { mismo sexo. }\end{array}$ \\
\hline \multirow{5}{*}{2016} & $\begin{array}{l}\text { El último país en } \\
\text { reconocer el matrimo- } \\
\text { nio entre personas del } \\
\text { mismo sexo ha sido } \\
\text { Ecuador. Lo ha hecho } \\
\text { por vía judicial después } \\
\text { de que la Corte Cons- } \\
\text { titucional haya emitido } \\
\text { un fallo histórico a } \\
\text { favor de estos matri- } \\
\text { monios y exige a la } \\
\text { Asamblea Nacional que } \\
\text { comience el proceso } \\
\text { de adecuación de la } \\
\text { norma. }{ }^{13}\end{array}$ \\
\hline
\end{tabular}

Cuadro de elaboración propia de los autores

\section{Aspecto antropológico}

La concepción del matrimonio en los tiempos pasados y actuales apuntala a la existencia de la unión del hombre y la mujer, tal como lo señala Condori (2017):

Nuestra concepción antropológica, hace patente el interés por comprender, en primera instancia, la razón que condicionó a la existencia y permanencia de la unión hombre - mujer, como hasta ahora se conoce al matrimonio, del fundamento y origen de esta pareja humana. Es necesario mencionar que se hace difícil hablar de un único y claro curso histórico del matrimonio, es decir no se presenta unidad de criterios tanto en el estudio antropológico, sociológico e histórico sobre el matrimonio en su inicio, pues los orígenes de la familia están ocultos todavía por las brumas de la prehistoria y estos además corren el riesgo de permanecer para siempre allí. Pese a esto pretendemos analizar y echar algunas luces sobre este afloramiento primigenio del matrimonio en la vida humana. (p.69)

No obstante, desde la perspectiva del siglo XXI, la figura del matrimonio desde el enfoque antropológico advierte

que existirían procesos particulares de apropiación subjetiva de los contenidos genéricos establecidos culturalmente, a lo que denominamos, siguiendo a Lamas (1993), identidad de género. Es así como las identidades se refieren a los procesos de formación de un sujeto, el cual raramente es absolutamente masculino o femenino, ni tampoco unívocamente femenino en el caso, de las personas de sexo mujer o masculino para los de sexo hombre, sino que una red de complejas interrelaciones entre los contenidos simbólicos existentes. (Díaz, 1995, p.55)

Por ello abordamos algunas concepciones antropológicas filosóficas del hombre, como son la existencialista de Sartre, la hedonista y la personalista para, de esa manera, tener una mayor comprensión del matrimonio de las personas del mismo sexo en la actualidad.

13 RTVE. "El matrimonio homosexual es ya legal en 30 países". Recuperado de:http://www.rtve.es/noticias/20190617/ solo-once-paises-del-mundo-esta-legalizado-matrimonio-homosexual/667560.shtml 


\section{Concepción existencialista del hombre de Sartre}

La corriente filosófica intitulada "el existencialismo del hombre", fue concebida por el filósofo francés, Jean Paul Sartre a inicios del siglo XX, quien consideraba que el ser humano poseía capacidades de razonamiento, conciencia, libertad y determinación; es decir era un ser indefinido que iba construyendo su propósito en la vida a través de la toma de decisiones. Sobre ello Echevarría (2006) denota que:

Sartre alcanza a exponer de manera brillante la idea que el "existencialismo" defiende ante todo y que justifica su nombre: "[En lo que corresponde al modo de ser de lo humano,] la esencia está precedida por la existencia"; es decir, lo que el ser humano es en cada caso, su consistencia fáctica, sólo se sostiene en la asunción libre que él hace de ella. El ser humano y el mundo de lo humano trascienden la necesidad que los determina como lo que deben ser en cada caso; el ser humano es libre y en su mundo se lee que es fruto de la libertad. Ser libre significa ser capaz de fundar, a partir de la anulación de una necesidad establecida, una "necesidad" diferente, de otro orden; una "necesidad" propia que es ella misma "innecesaria", gratuita, contingente, basada en la nada, sin encargo físico ni misión metafísica alguna que cumplir. (pp. 192-193)

Una afirmación central del existencialismo del filósofo Sartre es que "la existencia precede a la esencia", es decir, solo existiendo y actuando de cierta manera podemos obtener sentido en nuestras vidas, es decir no hay un diseño fijo de cómo debería ser un ser humano y ningún Dios que nos dé un propósito:

"El existencialismo declara que, si Dios no existe, hay por lo menos un ser en el que la existencia precede a la esencia, un ser que existe antes de poder ser definido por ningún concepto, y que este ser es el hombre, o como dice Heidegger, la realidad humana. ¿Qué significa aquí que la existencia precede a la esencia? Significa que el hombre empieza por existir, se encuentra, surge en el mundo, y que después se define." (Sartre, p.3)

Según esta concepción las personas homosexuales elegirían su sexualidad, basándose en que ésta se construye día a día, fruto de su libertad, puesto que el hombre no tiene una esencia acabada, su ser masculino o femenino se lo va construyendo. Con ello, muchas parejas del mismo sexo, mediante el uso de su autodeterminación, optarían por contraer nupcias teniendo en cuenta que ningún Dios, gobierno o sociedad puede señalar cuál es su sendero a construir y a seguir. No obstante, el existencialismo también conlleva al sentimiento de angustia a partir de la toma de decisiones.

\section{Concepción Hedonista}

La figura del hedonismo hace alusión a los placeres, deseos y banalidades en la sociedad contemporánea. Este concepto fue desarrollado por Epicuro en el momento de la decadencia en la época griega, quien señaló que el hedonismo era una figura que se limitaba a los deseos y giraba en torno a la ausencia del principio catastemático. 
Actualmente, el hedonismo ha generalizado la concepción de que la felicidad radica en la consecución del placer. Este se sitúa, más allá de los aspectos sociológicos de la cuestión, que no carecen de interés para quien se interesa en la marcha del mundo en el que se vive, algo a lo que no somos indiferentes en nuestro medio: que la búsqueda de la felicidad permanente, de la euforia perpetua, pretende lisa y llanamente eliminar el dolor y el sufrimiento, buscando hacer primar el Principio del Placer. (Fajnwaks, 2008, p.2)

El hedonismo se configura como una concepción teórica y práctica que busca el placer y la satisfacción momentáneas, que problematiza la felicidad, la hace consistir, por ejemplo, en estar a la moda (Trujano, 2013, p.90). Es propia de una sociedad de consumo.

Por ello, podemos describir que el matrimonio homosexual parte de una concepción hedonista porque se interrelaciona con principios prohibidos en la sociedad contemporánea, es decir no se limita a la base tradicional de amor entre un hombre y una mujer, por el contrario, no hay un orden estricto en ese razonamiento, considerando que deben hacer lo que les plazca y sientan gozo.

\section{Concepción personalista de Manuel Mounier}

La concepción personalista, es una corriente filosófica cuyo representante más insigne es el francés Manuel Mounier, que describe al ser humano en todas sus dimensiones y lo concibe como un ser libre, moral, independiente, capaz de tomar decisiones y asumir responsabilidades, y posee una formación intelectual y científica que le permiten su liberación fuera de prejuicios.
El enfoque que Mounier da al personalismo va en una clara orientación antropológica en su temática, partiendo desde una antropología abierta hacia la trascendencia, y un profundo sentido espiritual y ético en su desarrollo, asimismo, indica que el ser humano es un ser libre en todas sus expresiones, por ello posee la opción de elegir en una sociedad donde predomine el libre albedrío.

Según Montejo (2014)

El personalismo se levanta con intransigencia contra toda imposición que atente contra la dignidad de la persona. Por eso el personalismo no precisa ni doctrinarios ni moralistas, tan en uso, por ejemplo, en el campo religioso. Ni tampoco pseudopensadores tan extendidos en el mundo eclesial que pretenden pontificar sobre lo divino y lo humano, condicionando el comportamiento de sus incondicionales fieles, muchas veces sin escrúpulos de ningún tipo. Mounier califica igual de peligrosos a los doctrinarios como a los moralistas. (p.64)

Este enfoque personalista nos lleva a concebir al hombre, varón o mujer, como un ser abierto a la trascendencia y que se realiza en libertad, respetando su esencia de ser varón o mujer y un lugar donde este se realiza es en el matrimonio.

\section{LAS POSTURAS TEOLÓGICAS DEL MATRIMONIO HOMOSEXUAL}

\section{Postura de la Iglesia Católica}

Muchos de estos enfoques a favor de los denominados "matrimonios igualitarios" argumentan que es un derecho humano de formar una familia, 
pero nuestro análisis, en consonancia con el pensamiento de la iglesia católica, no se fundamenta en el concepto de familia, supone el concepto de familia nuclear, conformada por los esposos (varón y mujer) y los hijos. Nuestro enfoque del matrimonio católico se fundamenta en que éste es un sacramento y, consecuentemente, es válido para quienes profesamos la fe católica.

No cuestionamos la postura de algunas iglesias cristianas que sí lo admiten, como también la de algunos obispos católicos, como es la del obispo de la diócesis de Basilea en Suiza, quien a través de su vocero Hansruedi Huber, manifestó estar dispuesto a bendecir, en una ceremonia parecida a la del matrimonio católico, a parejas monoparentales aceptadas por la legislación civil ${ }^{14}$, pero esa no es la práctica ni la doctrina oficial de la iglesia católica; además se trata de una bendición, no propiamente de la celebración del sacramento del matrimonio.

La experiencia bíblica es que la humanidad está constituida por varones y mujeres y cuyo fin principal es la reproducción: "Dios creó al hombre a su imagen; a imagen de Dios los creó; hombre y mujer los creó. Dios los bendijo y les dijo: "sean fecundos y multiplíquense" (Gn 1,27-28).

Cuando un varón y una mujer se unen en matrimonio se constituyen en uno solo: "por ello el varón abandonará a su padre y a su madre y se unirá a su mujer y los dos serán una sola carne" (Gn 2,24). Claramente es un texto referido al matrimonio y con una apertura a la procreación. Esto no puede ser posible en parejas homosexuales ${ }^{15}$.

Jesús refuerza esta doctrina, cuando unos fariseos le preguntan si es lícito despedir a su mujer por cualquier motivo, a lo que Jesús responde con el texto del génesis 1,27 , reafirmando la doctrina de la indisolubilidad del matrimonio (Mt 19,3-5): "Así no son dos sino una sola carne. Aquello que Dios ha unido el hombre no puede separarlo" (Mt 19,6).

La tradición de la Iglesia, entendida principalmente como la práctica de la Iglesia a lo largo de su historia, ha mantenido la práctica y doctrina de que el sacramento del matrimonio válido es entre un varón y una mujer que libremente deciden unir sus vidas con la bendición de Dios y aceptan tener los hijos que puedan tener en su condición de esposos.

Algunos defensores del matrimonio católico homosexual aluden a testimonios de que, en la edad media, en la iglesia católica existía la práctica del matrimonio homosexual, conocida como adelfopoiesis (boda entre personas del mismo sexo), pero académicos católicos expertos en este tema afirman que no se trata de un verdadero matrimonio, sino más bien de una bendición a parejas homosexuales, además de que el contexto de estos matrimonios no es el mismo que el de hoy: "Pero la historia de la Iglesia es tan amplia que, de hecho, hubo una época en la que era la misma Iglesia la que realizaba uniones entre dos hombres, se llamaba "Adelfopoiesis" y, si

14 Información sustraída de: (https://www.sdpnoticias.com/diversidad/iglesia-catolica-apoya-matrimonio-igualitario-gay-suiza.html)

15 Congregación para la Educación Católica: "Hembra y varón los creó" (2019), donde se expresa que los debates actuales sobre la "identidad de género" no son sólo "ambiguos", sino que pueden "desestabilizar la institución familiar" 
bien no cuadra exactamente con nuestra idea contemporánea de "matrimonio homosexual", se le acerca mucho" (Cruz $R, 2019$ )

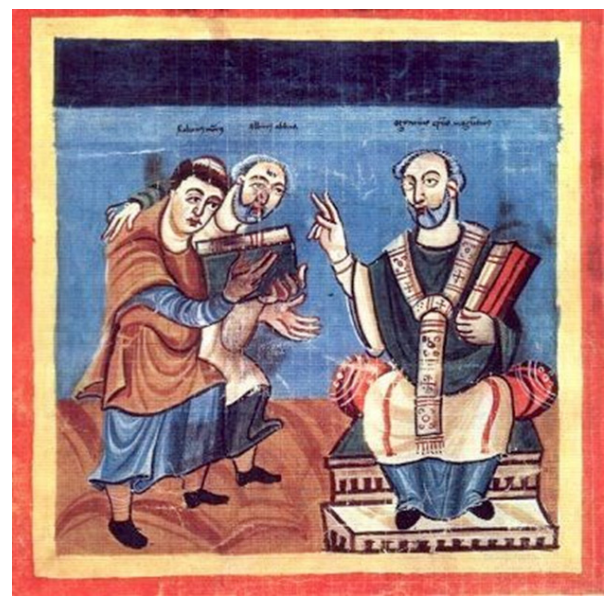

Ilustración medieval que ejemplifica una adelfopoiesis (Imagen: WikiCommons)

No encontramos en el Magisterio de la Iglesia documento alguno que justifique esta práctica. Lo ha expresado con claridad Monseñor Giacomo Morandi, secretario de la Congregación para la Doctrina de la $\mathrm{Fe}$, a propósito del documento de la Pontificia Comisión Bíblica "¿Quién es el hombre?" de que no existen en la tradición bíblica ejemplos de matrimonios homosexuales.

\section{Encontramos en el Catecismo de la} Iglesia Católica $(\mathrm{CIC})$ todo un tratado sobre el sacramento del matrimonio. Sacramento significa misterio, aludiendo de que éste es el signo del amor de Cristo a su Iglesia (CIC 1604). El matrimonio es un signo eficaz de la presencia de Cristo (CIC 1613.1617.2360), por lo que resulta claro que no puede ser elevada a la categoría de sacramento una unión homosexual.

El matrimonio constituye una alianza entre un varón y una mujer: "La alianza matrimonial es entre un hombre y una mujer bautizados, que expresan libremente su voluntad de contraer matrimonio" (CIC 1625), no puede ser de personas del mismo sexo, cuyos fines son el bien de los cónyuges y la procreación y educación de los hijos (CIC 1601). En la tradición se ha insistido mucho en el fin procreador de los esposos, que se enraíza en la naturaleza del ser humano y sigue siendo un fin primario, donde el hijo es visto como un don (CIC 2378), lo cual obviamente no es posible en una pareja homosexual. El otro fin primario es el bien de la pareja, lo que incluye el goce sexual que se experimenta en una relación sexual, que se constituye en un acto santo y querido por Dios (CIC 1604). Una pareja homosexual puede argumentar que eso sí es posible, pero será siempre un acto sexual antinatural.

Lo que la Iglesia y la sociedad en general buscan es garantizar que el niño crezca en un ambiente familiar, donde tanto la figura paterna como materna le sirvan de modelo, lo cual indudablemente no se puede dar en una pareja homosexual. He aquí porque aún en la sociedad civil resulta difícil la adopción de un niño por una pareja homosexual, a pesar de que estas parejas pueden argumentar que tienen ese derecho, pero también tienen que pensar que es un derecho del niño de tener la figura de padres heterosexuales. Muchos defensores de la adopción de niños por un matrimonio igualitario aducirán de que no se notan diferencias entre un niño crecido en una pareja heterosexual que uno de una pareja homosexual. El Dr. Irala, a propósito de la publicación del libro "Comprendiendo la homosexualidad", opina que no hay evidencias científicas de que esto sea correcto, más bien estas señalan que 
El mejor entorno, la mayor opción afectiva y educativa para un niño, es la de la pareja heterosexual establemente comprometida en el matrimonio. Esto no significa que una familia monoparental no pueda lograr la felicidad de los hijos, sino que, en términos generales, lo óptimo es la presencia de un padre y una madre. Dado que existen listas de espera de heterosexuales idóneos para la adopción en todos los lugares no parece lógico que los gobiernos contemplen otras alternativas de adopción porque es su deber ofrecer siempre lo mejor para estos niños (Irala, 2006)

Lo que la iglesia condena son las prácticas homosexuales, más no a los homosexuales ${ }^{16}$, para quienes debe tener una actitud pastoral de acogida, no discriminarlos: éstos deben "ser acogidos con respeto, compasión y delicadeza" (CIC 2358), cuando se trata de tendencias homosexuales instintivas, puesto que ellos no son culpables de esta tendencia, sino que más bien deben verlo como una prueba y la iglesia les hace un llamado a vivir la castidad (CIC 2359). La Iglesia, siguiendo la concepción bíblica, considera los actos homosexuales como intrínsecamente desordenados, como lo expresa la Congregación para la Doctrina de la fe (CDF: sobre la "persona humana", $N^{\circ} 8$ ), contrarios a la ley natural, cierran el acto sexual al don de la vida. Por lo tanto, no son aceptados en ningún caso (CIC 2357). Consecuentemente no se puede aceptar el matrimonio homosexual católico.
Si es cierto que la iglesia católica no acepta el matrimonio homosexual, es también plenamente cierto que, como parte de su misión evangelizadora recibida de Cristo, es la atención pastoral a estas parejas, sin discriminación de su opción sexual, la que han recibido de Cristo, ellos son verdaderos hijos de Dios. No se condena la tendencia homosexual, el hecho de que pueda haber un amor de pareja entre homosexuales que quieren compartir su vida, sus bienes, tutelar sus derechos civiles, al igual que cualquier pareja heterosexual ${ }^{17}$.

Hay sectores de la Iglesia católica que se oponen al matrimonio civil igualitario principalmente por la imagen que proyectaría ante el mundo, que los niños lo vean como algo normal o simplemente porque contrasta con nuestra cultura que ve el matrimonio heterosexual como lo natural. Para otros sectores, si se trata de salvaguardar los derechos civiles de una pareja homosexual, no ven por qué no incluirlo en su legislación; pero sólo se trata de un matrimonio civil, más no de un matrimonio católico.

\section{Postura de La Iglesia De Jesucristo de los Santos de los Últimos Días}

La Iglesia de Jesucristo de los Santos de los Últimos Días, iglesia restaurada por el profeta José Smith en la época de la última dispensación en la tierra, reconoce que el matrimonio es la unión de un varón y una mujer.

En la carta de fecha 14 de noviembre de 1991 concerniente a la importancia de

16 Son numerosos los documentos de la Iglesia Católica sobre la homosexualidad: Congregación para la

Doctrina de la Fe acerca de la atención pastoral para los homosexuales: Carta a los obispos católicos de la Iglesia Católica sobre la atención pastoral a las personas homosexuales" (1 de octubre de 1986). Exhortación Apostólica Postsinodal Amoris laetitia. "Dignitatis Personae": sobre algunas cuestiones de bioética (8 septiembre 2008).

17 Existe en la Iglesia un grupo denominado "Alentar", cuyo objetivo es ayudar a las familias y amigos de personas atraídas al mismo sexo 
la ley de castidad, la Primera Presidencia declaró: "Las relaciones sexuales son apropiadas sólo dentro de los lazos del matrimonio entre marido y mujer. Cualquier otra conducta sexual como la fornicación, el adulterio, o el comportamiento homosexual o lesbiano, es pecaminosa"

Asimismo, en la declaración intitulada "La Familia. Una proclamación para el mundo" indica que:

LA FAMILIA es ordenada por Dios. El matrimonio entre el hombre y la mujer es esencial para su plan eterno. Los hijos merecen nacer dentro de los lazos del matrimonio y ser criados por un padre y una madre que honran sus votos matrimoniales con completa fidelidad. La felicidad en la vida familiar tiene mayor probabilidad de lograrse cuando se basa en las enseñanzas del Señor Jesucristo. Los matrimonios y las familias que logran tener éxito se establecen y se mantienen sobre los principios de la fe, de la oración, del arrepentimiento, del perdón, del respeto, del amor, de la compasión, del trabajo y de las actividades recreativas edificantes. ${ }^{18}$

Es decir, reafirma que el matrimonio es la unión de un hombre y una mujer, siendo esencial para cumplir el plan de felicidad o salvación de nuestro Padre Celestial. Concerniente al matrimonio homosexual, la Iglesia de Jesucristo de los Santos de los Últimos Días (2003) ha expresado lo siguiente:

¿Qué actitud tiene su Iglesia con respecto a la homosexualidad? "En primer lugar, creemos que el matrimonio entre el hombre y la mujer fue decretado por
Dios. Creemos que el matrimonio puede ser eterno mediante el ejercicio del poder del sacerdocio sempiterno en la Casa del Señor. "La gente nos pregunta acerca de nuestra posición con respecto a aquellos que se consideran 'gays' o lesbianas. Mi respuesta es que los amamos como hijos e hijas de Dios; pueden tener ciertas inclinaciones que son poderosas y que pueden ser difíciles de dominar. (...) (p.26)

Tal como indica las sagradas escrituras del Libro de Mormón, otro testamento de Jesucristo, en el libro de $4 \mathrm{Nefi}$, en su capítulo 1, versículo 11: "Y se casaban y se daban en matrimonio, y fueron bendecidos de acuerdo con la multitud de las promesas que el Señor les había hecho", es decir se denota que el matrimonio como mandamiento del Señor debe efectuarse en unión de un hombre y una mujer, a fin de obtener bendiciones eternas

Dios nos creó "varón y hembra" tal como denota el libro de Doctrina y Convenios en el capítulo 20, versículo 18, y la Santa Biblia, en el libro de Génesis, capítulo 1, versículo 27, es decir, debemos detonar que la diferenciación de los sexos fue una característica esencial de nuestra existencia, y solo las uniones se efectuaban de esa manera.

Seguidamente, el objetivo de las personas que son miembros de la Iglesia de Jesucristo de los Santos de los Últimos Días es lograr la exaltación en el Reino Celestial y esto se logra únicamente habiendo realizado el convenio del matrimonio en un Santo Templo y expiando nuestros pecados. Tal como lo señala D y C 131: 1 -4:

18 La Iglesia de Jesucristo de los Santos de los Últimos Días, página oficial. La Familia una proclamación para el mundo. Recuperado de: https://www.churchofjesuschrist.org/topics/family-proclamation?lang=spa 
1 en la gloria celestial hay tres cielos o grados; 2 y para alcanzar el más alto, el hombre tiene que entrar en este orden del sacerdocio les decir, el nuevo y sempiterno convenio del matrimonio]; 3 y si no lo hace, no puede alcanzarlo. 4. Podrá entrar en el otro, pero ese es el límite de su reino; no puede tener aumento.

Finalmente, se debe señalar que nuestro Padre Celestial ama a cada de sus hijos sin distinción alguna, hasta a los más pecadores, no obstante, todos estamos dispuestos a arrepentirnos, por ello, no se debe juzgar a las personas por su condición, ideología u otra distinción; por el contrario, ayudarlos a venir a Cristo y que sientan su amor puro y sincero.

\section{CONCLUSIONES}

El matrimonio homosexual es sinónimo de que el mundo se encuentra en constantes cambios sociales, antropológicos, jurídicos e incluso teológicos, porque se tiene como finalidad no denigrar la dignidad de los agentes intervinientes.

El matrimonio homosexual debe ser estudiado desde una visión interdisciplinaria: social, jurídica, antropológica y teológica, para así tener una mayor compresión de cada postura y concepción de su naturaleza.

Desde un enfoque teológico el matrimonio homosexual no puede ser visto como un sacramento, pero sí estas parejas merecen todo el respeto y acompañamiento.

El matrimonio homosexual es sinónimo de matrimonio igualitario porque está reconocido social y jurídicamente en algunos estados del mundo occidental, que tienen como pilastra incluir al matrimonio homosexual como un tipo de familia en el siglo XXI.

\section{REFERENCIAS BIBLIOGRÁFICAS}

Arlettaz, F.(2015). Matrimonio homosexual y secularización. $1^{\circ}$ edición. México D.F. : UNAM, Instituto de Investigaciones Jurídicas.

Boscan, E. (2008). Homosexualidad: Los errores de concepto. Revista Trabajo Social $\mathrm{N}^{\circ} 18, p p .56-61$.

Díaz, P. (1995). Homosexualidad y Antropología: una Mirada desde el Género. II Congreso Chileno de Antropología. Colegio de Antropólogos de Chile A. G, Valdivia. Recuperado de: https:// www.aacademica.org/ii.congreso. chileno.de.antropologia/1 1.pdf

Catecismo de la Iglesia Católica (2005). Ciudad del vaticano: Edittrice Vaticana.

Chomali et al. (2008). Algunas consideraciones para el debate actual acerca de la homosexualidad. Antecedentes científicos, antropológicos, éticos y jurídicos en torno a las personas y las relaciones homosexuales. Recuperado de: https://www. bioeticaweb.com/wp-content/ uploads/2014/0 7/estudiohomosexualidad.pdf

Condori, D. (2017). Unión homosexual a la luz de la antropología jurídica del matrimonio. (tesis de grado, Universidad Católica de Santa María de Arequipa). Recuperado 
de: http://tesis.ucsm.edu.pe/ repositorio/bitstream/handle/UC SM/7 158/62.1 194.D.pdf?sequenc $\mathrm{e}=1$ EisAllowed $=\mathrm{y}$

Congregación para la Educación Católica (2019). Varón y mujer los creó. Para una vía de diálogo sobre la cuestión de gender en la educación. Ciudad del Vaticano

Cruz, R. (2019). ¿La Iglesia Católica realizaba matrimonios homosexuales en la Edad Media?. Recuperado de: https:// plumasatomicas.com/lgbt/iglesiamatrimonios-homosexuales-lgbtadelfopoiesis/

Echevarría, B. (2006). El Humanismo del Existencialismo. Diánoia, volumen LI, $N^{\circ}$ 57. pp. 189-199

Fajnwaks,F. (2008). Del《 hedonismo contemporáneo » como empuje al plus-de-gozar. Revista Virtualia $N^{\circ} 17$, pp. 1-5.

Irala (s.f.). Comprendiendo la homosexualidad. Consultado el 02-09-2020: http://www.fluvium. org/textos/sexualidad/sex132.htm

La Iglesia de Jesucristo de los Santos de los Últimos Días (2003). El Matrimonio Eterno. Recuperado de: https://www. churchofjesuschrist.org/bc/ content/shared/content/spanish/ pdf/language-materials/35311 spa.pdf
Martín, M. (2016). Los derechos de las parejas del mismo sexo en Europa. Estudio comparado. Revista Española de Derecho Constitucional, pp. 219-253. Recuperado de: http://dx.doi.org/10.18042/cepc/ redc. 107.07

Matzumoto, N. y Coronel, L. (2013). El matrimonio entre personas del mismo sexo: ¿derecho humano o concesión graciosa de los tolerantes? Revista Conflicto E Sociedad Vol. 1 - N², pp. 21-31

Morandi (s.f.). El documento sobre antropología no se abre a las uniones gays. Consultado el 0209-2020: https://www.vaticannews. va/es/vaticano/news/2019-12/ morandi-documento-biblicoantropologia-uniones-gays.html

Pontificia Comisión Bíblica (2019). Che cosa è l'uomo? Un itinerario di antropologia bíblica. Roma: Libreria Editrice Vaticana.

Tordesillas, E. (2016). El matrimonio entre personas del mismo sexo en Derecho Internacional Privado. Derechos civiles y derechos humanos afectados en diferentes países. Revista Universitas $N^{0} 24$, pp. 76-133

Trujano, M. (2013). Del hedonismo y las felicidades efímeras. Sociológica (México), 28(79), pp.79109. Recuperado de: http://www. scielo.org.mx/pdf/soc/v28n79/ v28n79a3.pdf

Fecha de recepción: 22-05-2020

Fecha de aceptación: 15-06-2020 